\title{
Tráfico de teorías y enseñanza: otro problema para el comparatismo
}

por Analía Gerbaudo

Universidad Nacional del Litoral - CONICET

En el último Congreso Internacional Orbis Tertius organizado por el Centro de Teoría y Crítica Literaria de la Universidad Nacional de La Plata en el año 2006, María Teresa Gramuglio presenta el ensayo "Tres problemas para el comparatismo". ${ }^{1}$ Dos años más tarde, durante el IV Argentino de Literatura celebrado en la Universidad Nacional del Litoral, vuelve (aunque con diferentes rodeos) sobre los mismos problemas y, cabe señalarlo, realiza sus puntualizaciones teóricas y metodológicas recuperando, como lo había hecho en el encuentro anterior, una práctica poco atendida desde la crítica literaria: la enseñanza. En los dos escritos enhebra reflexiones que surgen no sólo de sus actividades de investigación sino de un análisis de las decisiones que debe tomar a la hora de armar materias como "Literatura del siglo XIX" en la Universidad de Buenos Aires o "Literatura Europea" en la Universidad Nacional de Rosario (espacios curriculares que, como su nombre lo indica, atraviesan las fronteras de las literaturas nacionales). El análisis de esas decisiones se une a la lectura del estado de la cuestión del comparatismo y de los estudios literarios en general para precisar hipótesis de trabajo, líneas de investigación y problemas para los estudios comparados considerando especialmente los lugares de construcción teórica y metodológica existentes.

Más allá del envío a los artículos (el que se incluye en este número es la versión escrita de la presentación realizada en el marco del IV Argentino de Literatura) me interesa destacar lo que abren, ya que junto al punteo de las dificultades y los desafíos del comparatismo señalan orientaciones para cualquier investigación que pretenda inscribirse en esta línea: para reducir el riesgo de que las futuras producciones queden atrapadas en el simple racconto de influencias o en el cotejo más o menos lineal de los intercambios, no pueden obviarse los señalamientos que Gramuglio realiza. Las indagaciones que proyecten construir historias de la literatura, estudiar fenómenos literarios o culturales supranacionales o inscribir proyectos sobre relaciones interartísticas se verán enriquecidas por estas precisiones que se unen a las que desde una publicación reciente formula Miguel Dalmaroni: ${ }^{2}$ la decisión de incluir, junto a las líneas de investigación consolidadas en Argentina, otras emergentes como "literatura y pintura" y "literatura y enseñanza" anexando recomendaciones metodológicas, espacios de consulta bibliográfica, un resumen de los textos más relevantes de cada tradición y explicitaciones respecto de los protocolos de producción es un esfuerzo por democratizar saberes que operan en evaluaciones y adjudicaciones de subsidios y que rara vez se ponen en circulación 
de un modo tan claro y exhaustivo sin escatimar la inclusión de ejemplos y casos por temor a caer en "lo pedagógico".

En esta "agenda” en construcción de los estudios comparados me parece oportuno (es decir, aprovechando los antecedentes mencionados: marcas notables de movilidad del campo) inscribir un problema que se ve enriquecido por las observaciones teóricas y epistemológicas que Gramuglio realiza en el artículo que se incluye en este número de la revista: el estudio del tráfico de teorías realizado por los estudios literarios que se desarrollan en las universidades atendiendo especialmente a las repercusiones que esos movimientos (de importación, exportación, aplicación, reinvención categorial, etc.) producen en el campo de la enseñanza, se presenta como una zona de investigación abierta con desarrollos en curso en Argentina y en otros países de Sudamérica. ${ }^{3}$ La decisión de suscribir y fomentar esta perspectiva se ve alentada por dos tipos de aportes: por un lado, el que se esboza desde la crítica literaria que ha abierto líneas para los estudios comparados en Argentina y en América del Sur; por el otro, el que se gesta desde los lugares teóricos que nos ayudan a definir e interrogar nuestros problemas.

En relación al primero, destaco los nombres de dos colaboradores de esta revista: Daniel Link y Raúl Antelo. Ambos realizan acciones movilizadoras desde sus espacios de trabajo interrogando lo ya sabido y aceptado y abriendo nuevas zonas de puesta en contacto de objetos y problemas. Un recorrido por los libros de Link nos muestra a un escritor y a un crítico comprometido con una práctica inusual, también desvalorizada desde los sectores más ortodoxos de la crítica: la divulgación y la preocupación por la transferencia docente. Un recorrido por los de Antelo nos descubre a un investigador inquieto por inventar nuevos objetos de estudio que puedan no sólo responder a las preguntas que se van instalando en el seno de la cultura sino también inventar otras. Vale recuperar, a modo de ejemplo, un texto que permitirá recordar una intervención poco difundida en Argentina debido al constante problema de la circulación, escasa y discontinua, de nuestras publicaciones (incluyo en el colectivo a todas las editadas en Sudamérica). Durante su presidencia de ABRALIC (Associaçao Brasileira de Literatura Comparada) Antelo organiza junto a Ana Luiza Andrade y María Lucía de Barros Camargo el sexto congreso de la asociación en la Universidade Federal de Santa Catarina. El encuentro tiene lugar en agosto de 1998 y se caracteriza por actuar, no el tolerantismo-intolerante, ${ }^{4}$ sino la verdadera hospitalidad. Aquella que hace lugar a la voz del otro permitiéndole la expresión, seguramente no compartida, de la perspectiva que le permite explicar en qué consiste "comparar" en ese momento, desde sus parámetros y desde su posición teórica. Lecturas do ciclo, el texto que reúne las conferencias de aquel encuentro, documenta esta actitud política y este modo de situarse dentro de la institución universitaria: no sólo exhibe la inusual convivencia de posiciones extremadamente diversas sobre el campo de los estudios literarios (no de otro modo puede entenderse la generación de un espacio en el que interactúan Tania Franco Carvalhal y Beatriz Sarlo, Roberto Schwarz y Adriana Rodríguez Pérsico, Eduardo Coutinho y Susan Buck-Morss) sino que, aunque de modo oblicuo, desde la contratapa y desde una breve presentación, los organizadores exponen lo que su trabajo actúa (y remarco este verbo como un modo de señalar la traducción efectiva de lo declarado en prácticas). ${ }^{5}$

En relación al segundo tipo, considero pertinente volver a poner en circulación y en discusión los aportes conceptuales que permiten defender la creación de espacios 
intercientíficos. Retomo en especial dos: interciencia e invaginación según Jacques Derrida. Dos términos anudados no sólo por su vecindad teórica sino también por las acciones que Derrida ha promovido en relación a las instituciones de investigación y de enseñanza. Recojo dos. Sus intervenciones tanto para la fundación del GREPH (Groupe de Recherches sur l'enseignement philosophique) como para la creación del Collège International de Philosophie en las décadas del setenta y del ochenta están motivadas en la necesidad de hacer lugar a lo que no tenía cabida dentro de las instituciones oficiales: la discusión sobre el sentido de la enseñanza de la filosofía y la apertura de un espacio que permitiera alojar las investigaciones que promovieran el tratamiento de problemas intercientificos. Concepto que no presenta los límites de la interdisciplinariedad, marcada más bien por una cooperación programada entre los representantes de ciencias constituidas que estudian un objeto común e identificado en sus contornos sirviéndose de métodos y procedimientos fijados de antemano, pero sin liberar las problemáticas de los protocolos de las disciplinas tal como están armadas y, por lo tanto, con pocas posibilidades de provocar o multiplicar interrogantes, de aportar nuevas resoluciones o de inventar unidades de investigación. ${ }^{6}$ Promover un trabajo intercientífico no supone abolir los límites disciplinares sino desarrollar acciones más pendientes de lo por-venir (de lo que pueda irrumpir o crearse a partir de esa intersección) que del cuidado de la invariabilidad de unos bordes que Derrida suele imaginar invaginados, es decir, incluyendo (aunque sin absorber) el afuera en el adentro, lo otro en lo propio. ${ }^{7}$ Una zona hospitalaria, abierta a nuevas preguntas, a im-pensadas formas de respuesta, a confluencias monstruosas que, probablemente, emerjan bajo la forma del peligro absoluto para muchos.

Cabe subrayar que la lucha por la creación y el sostenimiento de espacios intercientíficos y transdisciplinares tiene en esta revista y en el Centro desde el cual se produce, más de una historia por contar: el esfuerzo de su directora, del equipo editor, del Centro de Publicaciones de la Universidad Nacional del Litoral y de investigadoras de otras universidades y colaboradoras permanentes de la revista (como Susana Romano Sued y Pampa Arán que desde los inicios alentaron la configuración de un espacio como éste que atendiera a las reflexiones que se producen en zonas de borde disciplinar, entre la literatura y la didáctica, entre la teoría y la filosofía, entre la epistemología de la teoría literaria y de la lingüística, entre la historia de la literatura y la crítica literaria), encuentra en este nuevo número otra muestra de los desarrollos que pudimos ir consolidando desde su fundación.

Sigo pensando a esta revista como un espacio en el que tienen voz tanto los investigadores con larga experiencia en el campo como los jóvenes que escriben sus primeros papeles de investigación y los imagino a cada uno de ellos en una actitud similar a la de Judith Butler cuando descubre que los libros que quería "filosóficos" son ubicados por sus lectores en el estante de "teoría literaria". Coherente con la teoría de la performatividad que en parte suscribe, aprovecha la instancia para re-preguntar(se): cuenta que cuando empieza a publicar sobre género, recibe invitaciones para hablar de algo que los demás llamaban "teoría" cuando ella suponía que debían invitarla para hablar de "filosofía". El desconcierto inicial ante el efecto de sus intervenciones la llevan a revisar qué tipo de práctica era la "teoría" (aquella que solía identificar con los escritos de Paul De Man, René Wellek, Harold Bloom, entre otros) y luego, qué tipo de práctica era la filosofía (o en qué se había convertido o se estaba convirtiendo la teoría y también la filosofía). La 
perplejidad y la ansiedad primeras se aplacan cuando descubre que bajo el rótulo de "filosofía" aparecen la obras de varios escritores cuyos trabajos no se enseñan en los departamentos de filosofía; también cuando advierte que es cada vez mayor el número de estudiantes de humanidades interesados en los escritos de Jacques Derrida o de Giorgio Agamben. ${ }^{8}$

Esta anécdota tiene lugar en esta presentación porque revela, desde otro registro autobiográfico, tanto el sentido de una apuesta por el trabajo transdisciplinar e intercientífico como la valoración de un efecto de lectura insospechado y también, por qué no, porque presenta una colección de ejemplos sobre tráficos de teorías en la que, en parte, puede leerse la inquietud por dejar una enseñanza o la transferencia de una posición.

\section{Notas}

${ }^{1}$ Este trabajo fue publicado más tarde en el número 12 de la revista Orbis Tertius (cf. www.orbistertius.unlp.edu.ar).

${ }^{2}$ Dalmaroni, M. (dir.): (2008) La investigación literaria. Problemas iniciales de una práctica. UNL, Santa Fe.

${ }^{3}$ Cf. Alzate, C. (ed.): (2008) Literatura, prácticas críticas y transformación cultural. Universidad Nacional de Colombia, Bogotá.

${ }^{4}$ Esta expresión está tomada del "Epílogo" que Juan Carlos Moreno Romo escribe a su traducción de El mito nazi de JEAN LuC-NANCY y PHILIPE LACOUE-LABARTHE (Anthropos, Barcelona, 2002) y permite introducir la distinción entre tolerancia y hospitalidad, es decir, entre una recepción "caritativa" y una acogida no condicionada del arribante que es respetado en su singularidad sin señalarle que se le abre un espacio, que se le hace un lugar, pero a condición de que no olvide que está habitando en casa ajena, en territorio del otro, del "más fuerte", del que tiene el poder (cf. Derrida, J.: "Auto-immunités, suicides réels et symboliques. Un dialogue avec Jacques Derrida". Le "concept" du 11 septembre. Dialogues à New York (octobre-décembre 2001) avec Giovanna Borradori. Galilée, Paris, 2003, 186-187.

${ }^{5}$ Cf. Antelo, R., Andrade, A. y De Barros Camargo, L.: (1999) Leituras do ciclo. Grifos, Santa Catarina.

${ }^{6}$ Derrida, J., Chatêlet, F., Faye, J. y Lecourt, D.: (1998) Le Rapport bleu. Les sources historiques et théoriques du Collège International de Philosophie. Presses Universitaires de France, Paris, 7-43.

${ }^{7}$ Derrida, J.: (2001) Papier Machine. Le ruban de machine à écrire et autres réponses. Galilée, Paris, 318.

${ }^{8}$ Butler, J.: (2004) Deshacer el género. Paidós, Buenos Aires, 2006, 343-345. 